\title{
Real-World Evidence in Prescription Medication Use Among U.S. Adults with Neck Pain
}

\author{
Jin-Feng Huang · Zhou Meng · Xuan-Qi Zheng · Zongshi Qin • \\ Xiao-Lei Sun · Kai Zhang · Hai-Jun Tian • Xiao-Bing Wang • \\ Ze Gao $\cdot$ Yan Michael Li $\cdot$ Ai-Min Wu
}

Received: July 9, 2020 / Published online: September 17, 2020

(C) The Author(s) 2020

\begin{abstract}
Introduction: Neck pain is a common condition that leads to serious pain, disability, and increased healthcare costs worldwide. Pharmacotherapy is one of the most common strategies to reduce neck pain in patients. The aim of this study was to analyze the real-world pattern of drugs prescribed for patients with neck pain in the USA.
\end{abstract}

Digital Features To view digital features for this article go to https://doi.org/10.6084/m9.figshare.12800309.

J.-F. Huang · X.-Q. Zheng · A.-M. Wu ( $₫)$

Department of Orthopaedics, The Second Affiliated

Hospital and Yuying Children's Hospital of

Wenzhou Medical University, Wenzhou 325027,

Zhejiang, People's Republic of China

e-mail: aiminwu@wmu.edu.cn

\section{Z. Meng}

Department of Medicine, University of Maryland

Medical Center Midtown Campus, Baltimore, MD

21201, USA

Z. Qin

Li Ka Shing Faculty of Medicine, School of Chinese

Medicine, The University of Hong Kong, Pok Fu

Lam, Hong Kong, China

X.-L. Sun

Department of Orthopaedics, Tianjin Hospital,

Tianjin 300210, People's Republic of China

K. Zhang · H.-J. Tian

Shanghai Key Laboratory of Orthopaedic Implants,
Methods: Data on individuals who reported current neck pain in the 2009-2010 US National Health and Nutrition Examination Survey (NHANES) and with a history of persistent pain for at least 6 weeks or 3 months were extracted from the NHANES database. Those included in the study were divided into three groups based on the duration of pain: the without neck pain group (Group A); subacute group (Group B) with a history of 6 weeks of neck pain; and the chronic neck pain group (Group C) with a history of 3 months of neck pain. The use and duration of medication

Department of Orthopaedics, Ninth People's Hospital, Shanghai Jiaotong University School of Medicine, Shanghai, People's Republic of China

\section{X.-B. Wang}

Department of Rheumatology, The First Affiliated Hospital of Wenzhou Medical University, Wenzhou, People's Republic of China

\section{Z. Gao}

Department of Orthopaedic Surgery, The Third Hospital of Hebei Medical University, Shijiazhuang, People's Republic of China

Y. M. Li (ه)

Department of Neurosurgery and Oncology, School of Medicine and Dentistry, University of Rochester Medical Center, Rochester, NY 14642, USA e-mail: yanm_li@urmc.rochester.edu 
prescribed for Group A, B, and C patients were compared.

Results: The analysis revealed that opioid use was significantly more prevalent in the subacute and chronic neck pain group than in the without neck pain group (Group A) (adjusted odds ratio [aOR] 4.20, 95\% confidence interval [CI] 2.07-8.52 and aOR 7.00, 95\% CI 4.32-11.33, respectively). The factors strongly associated with higher opioid use included older age, low education level, and low family income. In the chronic neck group, opioids, followed in decreasing order of frequency by acetaminophen and nonsteroidal anti-infammatory drugs, were the most common analgesics used in combination with other analgesics.

Conclusion: Our analysis of the data shows that the long-term excessive use of opioids and the underutilization of other analgesics are two major issues in the treatment of neck pain in the USA. Possible improvements include improved education of patients by healthcare professionals on the use of opioids and more consideration given to non-pharmacotherapy options. Our results reveal the potential problem in pharmacotherapy choices for neck pain treatment and may help improve the current clinical practice in the USA and other countries.

Keywords: Neck pain; Opioids; Prescription medication; Real-world evidence

\section{Key Summary Points}

\section{Why carry out this study?}

Neck pain is currently a common condition that leads to serious pain, disability, and increased healthcare costs worldwide.

Pharmacotherapy is one of the most common strategies to reduce neck pain. Information on the pattern of medication use among U.S. adults with neck pain is scarce.

The aim of this study was to analyze the real-world pattern of drugs prescribed for patients with neck pain in the USA.

\section{What was learned from the study?}

Long-term excessive use of opioids and the underutilization of other analgesics are two major issues in the treatment of neck pain in the USA. Older age, low education level, and low family income were found to be strongly associated with more opioid use.

In patients with chronic neck pain, opioids, followed in order of decreasing frequency by acetaminophen and nonsteroidal anti-inflammatory drugs, were the most common analgesics used in combination with other analgesics.

Healthcare professionals should better educate patients on the use of pain medications and consider more nonpharmacotherapy options.

\section{INTRODUCTION}

Neck pain is a common condition that leads to serious pain, disability, and increased healthcare costs worldwide [1-3]. Increasingly more researchers are finding that effective treatment and prevention strategies for neck pain are needed [1, 4]. Pharmacotherapy, including opioids, non-steroidal anti-inflammatory drugs (NSAIDs), and paracetamol, is one of the most common strategies to reduce neck pain reduction in the USA $[5,6]$. The U.S. Centers for Disease Control and Prevention released a guideline for prescribing opioids which pointed out that non-pharmacologic therapy and nonopioid pharmacologic therapy should be the preferred treatments for chronic pain [7]. Opioids only should be used after careful consideration and only for short- to medium-term treatment [8]. Previous studies have shown that excessive opioid use for neck pain is very common in the USA [9-12].

The USA has a long history of opioid use and has thereby accumulated a lot of experience in opioid management. This experience could offer important lessons for other countries in 
their own efforts to effectively manage opioid use. There is currently a worldwide increase in the demand for prescription opioids, and excessive use of opioids is becoming a serious global problem [13]. Therefore, learning from the USA in terms of managing opioid use is important for other countries [14].

Information on the pattern of medication use among U.S. (i.e., American) adults with neck pain is scarce. Real-world evidence can be helpful in the decision-making process related to therapeutic regimens, drug development, prescribing behavior, patient care, among other factors [15]. However, real-world data on the use patterns of prescription medication for the treatment of neck pain is limited. Therefore, the aim of our study was to analyze the pattern of prescription medication use in neck pain in the USA. Our results also show the demographic characteristics of opioid use in the neck pain population which is helpful for reducing the use of opioids.

\section{METHODS}

\section{Data Source and Study Participants}

Data for this study were collected from the National Health and Nutrition Examination Survey (NHANES) database by a professional statistician. The aim of NHANES is to assess the health and nutritional status of the U.S. adult population [16]. All survey protocols used by the NHANES are evaluated by the National Center for Health Statistics (NCHS) research ethics board and informed consent must be provided [17]. For our study, we used data extracted from the 2009-2010 survey because this survey cycle included a comprehensive neck pain questionnaire administered to participants aged 20-69 years. The neck pain sample was defined as participants in the survey who reported current neck pain at the time of the survey and had a history of persistent pain for at least 6 weeks or 3 months. Participants with cancer, fracture, gout, arthritis (including rheumatoid arthritis, osteoarthritis, psoriatic arthritis, and other arthritis), iritis/uveitis, ulcerative colitis, and Crohn's disease were excluded from our study, as these conditions might affect the use of analgesics.

The authors of a previous study reported that methadone, buprenorphine, buprenorphine, and naloxone were often used to treat opioid dependence or withdrawal [18]. Therefore, we excluded subjects who use these opioids from our study in order to reduce the impact of opioid dependence on our results.

Participants without neck pain were categorized into Group A $(n=3035)$; those with a history of 6 weeks of neck pain were categorized into Group B $(n=158)$; and participants with a history of 3 months of neck pain were categorized into Group C $(n=308)$. Data extracted from the NHANES database include demographic characteristics (age, sex, race, body mass index [BMI]), education level, annual family income, Patient Health Questionnaire 9 (PHQ9) score, work pattern (vigorous and moderate work), exercise pattern (vigorous and moderate exercise), health conditions (medical comorbidities), extent of pain relief from medications (none, some, most, or all of the pain released) and sleep quality (sleep $<4 \mathrm{~h}$ due to pain).

\section{Use of Prescription Medications}

Information on the use of prescription medications was collected during the survey by an interviewer in the participants' homes. The interviewer documented the prescription medications that had been used by the participants within the past 30 days, also requesting to view the prescription bottles, when available, to record the duration of use of each prescription medication. The most common analgesics used for neck pain were found to be opioids, acetaminophen, NSAIDs, salicylates, cyclooxygenase 2 (COX-2) inhibitors, gabapentin, topical lidocaine, muscle relaxants, duloxetine, tricyclic antidepressants, and benzodiazepines. Some anti-depression medications not typically used for pain relief were also identified, including selective serotonin reuptake inhibitors (SSRIs) and non-benzodiazepine hypnotics. 


\section{Statistical Analysis}

Groups A, B, and C were compared for the use and duration of prescription medications. Analysis of variance (ANOVA) was used for the comparison of continuous variables and the Chi-square test was used for the comparison of categorical variables.

The characteristics of the participants in Groups A, B, and C were compared by ANOVA for continuous variables and by the Chi-square test for categorical variables. The frequency of the use of various drug combinations was then calculated, and the demographic characteristics of prescription medication use by the participants were determined. Logistic regression was also used to calculate adjusted odds ratios (aOR), which were adjusted for age, race, education level, gender, annual family income, PHQ9 score, and medical comorbidities.

All statistical analyses were conducted using SPSS software version 18 (IBM Corp., Armonk, NY, USA). A $P$ value of $<0.05$ was considered to indicate statistical significance.

All data were obtained from NHANES directly in de-identified form, and thus this study did not require additional Institutional Review Board (IRB) approval.

\section{RESULTS}

The demographic characteristics of the different groups are shown in Table 1 . Women were more likely to develop subacute neck pain $(62.0 \%)$ and chronic neck pain $(58.1 \%)$, and patients from low-income families were found to be prone to develop subacute neck pain and chronic neck pain. In addition, patients with subacute and chronic neck pain were more likely to suffer from depression and were had more strenuous work patterns.

The prevalence of prescription medication use among patient with subacute neck pain, chronic neck pain, and no neck pain is shown in Table 2. In the subacute and chronic neck pain groups opioids were the mostly highly used analgesics (7.0 and $12.3 \%$ of subjects, respectively) and SSRIs were the mostly used antidepressants drug $(9.5$ and $12.3 \%$, respectively). Opioid use was significantly more prevalent in the subacute and chronic neck pain group than in the no-neck pain group (aOR 4.20 , 95\% confidence interval [CI] 2.07-8.52 and aOR 7.00, 95\% CI 4.32-11.33, respectively). The use of acetaminophen, NSAIDs, muscle relaxants, and gabapentin was much more common in the chronic neck pain group than in the no-neck pain group (aOR 6.44, 95\% CI 4.02-10.30; aOR 4.63, 95\% CI 2.91-7.37; aOR 7.66, 95\% CI 3.90-15.06; aOR: 8.88, 95\% CI $3.62-21.77$, respectively). In addition, duloxetine and COX-2 inhibitors were also medications of preference by chronic neck pain patients (aOR 4.02, 95\% CI 1.52-10.60 and aOR 5.06, 95\% CI 1.59-16.09, respectively). However, tricyclic antidepressants and topical lidocaine were rarely used by both groups. The prevalence of hypnotics was also higher in subacute and chronic neck pain patients than in those without neck pain (7.6 and 5.8\%, respectively).

Analysis of the median duration of prescription medication use revealed that the duration of opioid use was significantly longer in the subacute and chronic neck pain groups (mean duration 243 and 395 days, respectively) than in the non-neck pain group (mean duration 36 days) (Table 3 ). In the chronic neck pain group, the median duration of acetaminophen and NSAID use was 1095 and 319 days, respectively.

The frequency of various drug combinations used by the chronic neck pain population is shown in Fig. 1. Opioids, followed in decreasing order of frequency by acetaminophen, NSAIDs, and muscle relaxants, were the most common analgesics combined with other analgesics. The most common combination used by the chronic neck pain population was opioids with acetaminophen or NSAIDs (3.6\%). Other common combinations include opioids with muscle relaxants, SSRIs, benzodiazepines, or hypnotics $(2.3 \%)$ and opioids with gabapentin (1.60\%).

Subgroup analysis by demographic characteristics was conducted for the chronic neck pain group (Fig. 2). Opioid use in the chronic neck pain population was found to be most common among patients aged $>60$ years $(21.7 \%)$, non-Hispanic blacks (16.5\%), those 
Table 1 Demographic and behavioral characteristics of the American adults aged 20-69 years with no neck pain, subacute neck pain, and chronic neck pain

\begin{tabular}{|c|c|c|c|c|}
\hline \multirow{2}{*}{$\begin{array}{l}\text { Demographic and } \\
\text { behavioral characteristics }\end{array}$} & \multicolumn{3}{|l|}{ Study patient groups } & \multirow[t]{2}{*}{$P$ value } \\
\hline & $\begin{array}{l}\text { Group A: without } \\
\text { neck pain }(n=3035)\end{array}$ & $\begin{array}{l}\text { Group B: with subacute } \\
\text { neck pain }(n=158)\end{array}$ & $\begin{array}{l}\text { Group C: with chronic } \\
\text { neck pain }(n=308)\end{array}$ & \\
\hline Age (years) & $43.43 \pm 16.14$ & $42.09 \pm 13.94$ & $45.85 \pm 12.03$ & $<0.001$ \\
\hline BMI $\left(\mathrm{kg} / \mathrm{m}^{2}\right)$ & $28.60 \pm 6.39$ & $27.72 \pm 8.29$ & $28.87 \pm 7.56$ & 0.194 \\
\hline Gender & & & & $<0.001$ \\
\hline Male & $1580(52.1 \%)$ & $60(38.0 \%)$ & $129(41.9 \%)$ & \\
\hline Female & $1455(47.9 \%)$ & $98(62.0 \%)$ & $179(58.1 \%)$ & \\
\hline Race & & & & 0.667 \\
\hline Non-Hispanic White & $1501(49.5 \%)$ & $81(51.3 \%)$ & $141(45.8 \%)$ & \\
\hline Non-Hispanic Black & $544(17.9 \%)$ & $24(15.2 \%)$ & $53(17.2 \%)$ & \\
\hline Mexican American & $565(18.6 \%)$ & $28(17.7 \%)$ & $57(18.5 \%)$ & \\
\hline Other Hispanic & $279(9.2 \%)$ & $16(10.1 \%)$ & $37(12.0 \%)$ & \\
\hline $\begin{array}{l}\text { Other race-including } \\
\text { multi-racial }\end{array}$ & $146(4.8 \%)$ & $9(5.7 \%)$ & $20(6.5 \%)$ & \\
\hline Education & & & & 0.326 \\
\hline College and higher & $671(22.1 \%)$ & $31(19.6 \%)$ & $53(17.2 \%)$ & \\
\hline $\begin{array}{l}\text { High school/Associate's } \\
\text { degree }\end{array}$ & $1570(51.7 \%)$ & $83(52.5 \%)$ & $173(56.2 \%)$ & \\
\hline Less than high school & $794(26.2 \%)$ & $44(27.8 \%)$ & $82(26.6 \%)$ & \\
\hline Annual family income (US\$) & & & & 0.066 \\
\hline$>100,000$ & $444(14.6 \%)$ & $18(11.4 \%)$ & $27(8.8 \%)$ & \\
\hline $65-99,000$ & $409(13.5 \%)$ & $20(12.7 \%)$ & $39(12.7 \%)$ & \\
\hline $45-64,000$ & $408(13.4 \%)$ & $20(12.7 \%)$ & $41(13.3 \%)$ & \\
\hline $20-44,000$ & $1026(33.8 \%)$ & $51(32.3 \%)$ & $105(34.1 \%)$ & \\
\hline$<20,000$ & $748(24.6 \%)$ & $49(31.0 \%)$ & $96(31.2 \%)$ & \\
\hline PHQ9 score (depression) & & & & $<0.001$ \\
\hline $0-4$ (non-depression) & $2306(76.0 \%)$ & $100(63.3 \%)$ & $162(52.6 \%)$ & \\
\hline 5-9 (mild depression) & $487(16.0 \%)$ & $29(18.4 \%)$ & $68(22.1 \%)$ & \\
\hline $\begin{array}{l}\text { 10-14 (moderate } \\
\text { depression) }\end{array}$ & $163(5.4 \%)$ & $12(7.6 \%)$ & $37(12.0 \%)$ & \\
\hline $\begin{array}{l}\text { 15-19 (moderate-severe } \\
\text { depression) }\end{array}$ & $54(1.8 \%)$ & $12(7.6 \%)$ & $27(8.8 \%)$ & \\
\hline 20-27 (severe depression) & $25(0.8 \%)$ & $5(3.2 \%)$ & $14(4.5 \%)$ & \\
\hline
\end{tabular}


Table 1 continued

\begin{tabular}{|c|c|c|c|c|}
\hline \multirow{2}{*}{$\begin{array}{l}\text { Demographic and } \\
\text { behavioral characteristics }\end{array}$} & \multicolumn{3}{|l|}{ Study patient groups } & \multirow[t]{2}{*}{$P$ value } \\
\hline & $\begin{array}{l}\text { Group A: without } \\
\text { neck pain }(n=3035)\end{array}$ & $\begin{array}{l}\text { Group B: with subacute } \\
\text { neck pain }(n=158)\end{array}$ & $\begin{array}{l}\text { Group C: with chronic } \\
\text { neck pain }(n=308)\end{array}$ & \\
\hline \multicolumn{5}{|l|}{ Work pattern } \\
\hline Vigorous work & $601(19.8 \%)$ & $49(31.0 \%)$ & $72(23.4 \%)$ & $<0.001$ \\
\hline $\begin{array}{l}\text { Vigorous work } \\
\text { time (minutes/day) }\end{array}$ & $201.73 \pm 426.12$ & $216.02 \pm 198.19$ & $222.46 \pm 160.09$ & 0.897 \\
\hline Moderate work & $1149(37.9 \%)$ & $66(41.8 \%)$ & $130(42.2 \%)$ & 0.221 \\
\hline $\begin{array}{l}\text { Moderate work } \\
\text { time (minutes/day) }\end{array}$ & $166.04 \pm 319.82$ & $157.27 \pm 128.90$ & $158.57 \pm 136.03$ & 0.943 \\
\hline \multicolumn{5}{|l|}{ Reaction exercise } \\
\hline Vigorous reaction exercise & $723(23.8 \%)$ & $35(22.2 \%)$ & $48(15.6 \%)$ & $<0.01$ \\
\hline $\begin{array}{l}\text { Vigorous reaction exercise } \\
\text { time (minutes/day) }\end{array}$ & $79.11 \pm 59.09$ & $73.86 \pm 63.24$ & $75.63 \pm 43.20$ & 0.816 \\
\hline Moderate reaction exercise & $1275(42.0 \%)$ & $65(41.1 \%)$ & $107(34.7 \%)$ & 0.180 \\
\hline $\begin{array}{l}\text { Moderate reaction exercise } \\
\text { time (minutes/day) }\end{array}$ & $67.57 \pm 57.16$ & $58.46 \pm 62.36$ & $61.79 \pm 59.65$ & 0.302 \\
\hline Medical comorbidities & & & & $<0.001$ \\
\hline $0-1$ & $2462(81.1 \%)$ & $98(62.0 \%)$ & $191(62.0 \%)$ & \\
\hline $2-3$ & $521(17.2 \%)$ & $52(32.9 \%)$ & $96(31.2 \%)$ & \\
\hline$>3$ & $52(1.7 \%)$ & $8(5.1 \%)$ & $21(6.8 \%)$ & \\
\hline
\end{tabular}

Values in table are given as the mean \pm standard deviation $(\mathrm{SD})$ or as a number with the percentage in parenthesis BMI Body mass index, $P H Q 9$ Patient Health Questionnaire 9

with a annual family income lower < US\$ $20,000(13.8 \%)$, and those with a lower education level (10.9\% among those with a GED/AA degree [GED/AA is equivalent to a high school diploma] and $16.7 \%$ among those with less than high school education compared with $4 \%$ use among those with a college degree and higher). In addition, patients of older age and those with a lower education level, as well as female patients, were more likely to use acetaminophen and NSAIDs. Subsequent analysis of the risk factors for chronic neck pain patients to use opioids, NSAIDs, and muscle relaxants revealed that older age, lower education level, and lower family income were strongly associated with increased opioid use. We also found that male patients and patients with more comorbidities $(>3)$ were more likely to use acetaminophen for pain relief and that patients with depression were more likely to use NSAIDs. However, age, education level, and family income did not affect the use of acetaminophen, NSAIDs, and muscle relaxants: the aOR (95\% CI) was 2.27 (1.02-5.19) for the GED/ AA degree group and 4.12 (1.40-12.1) for those with less than a high school education compared with those with a college degree or higher (Table 4). 


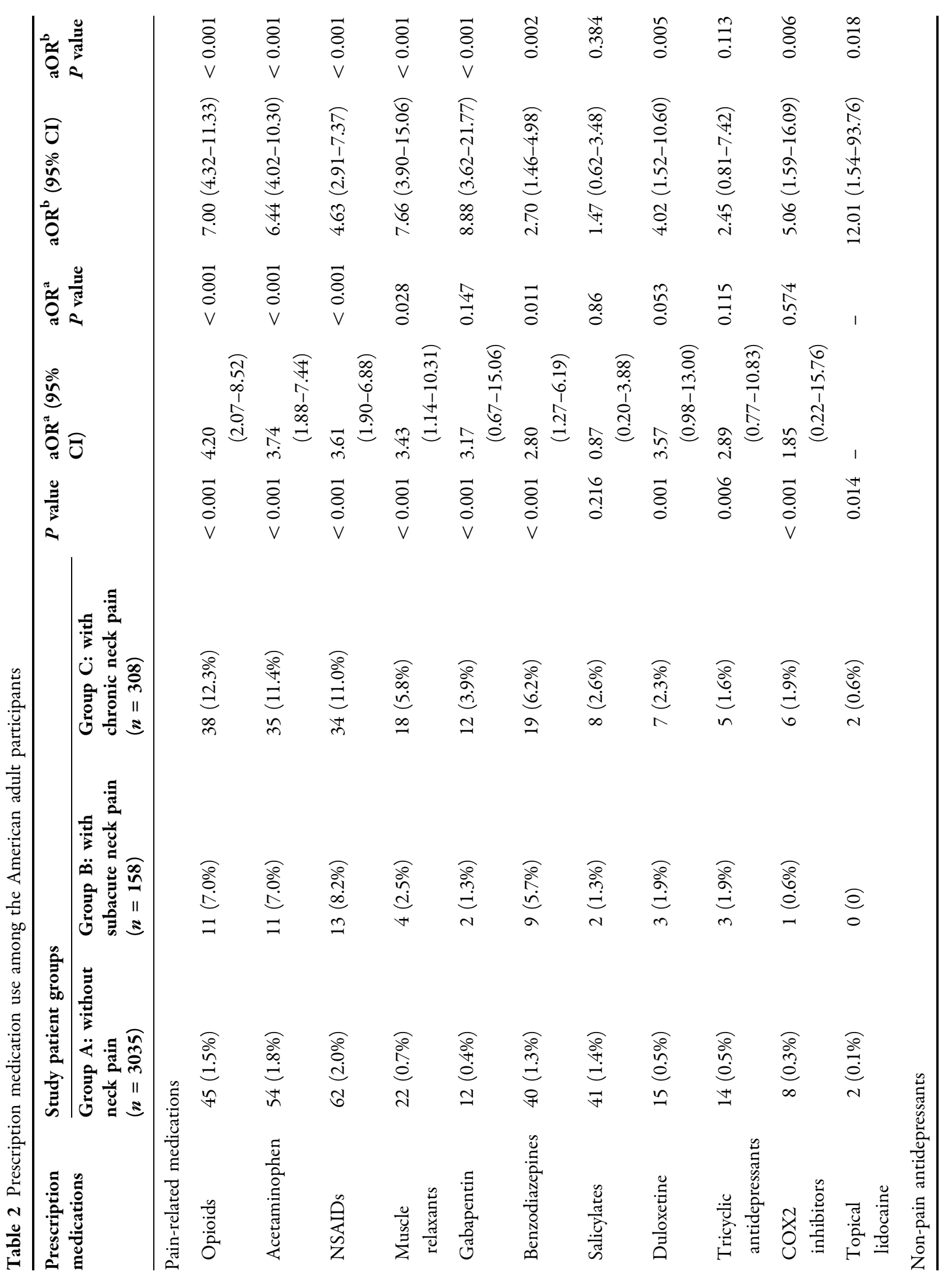




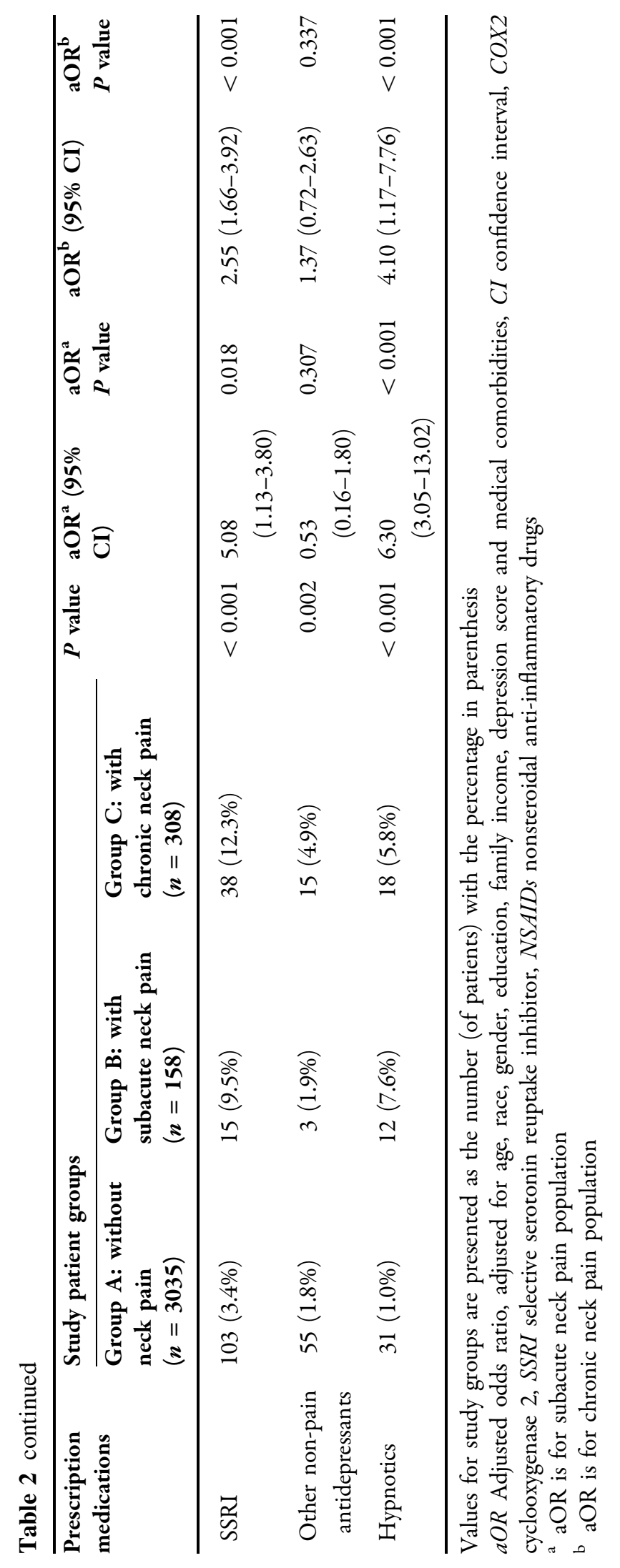




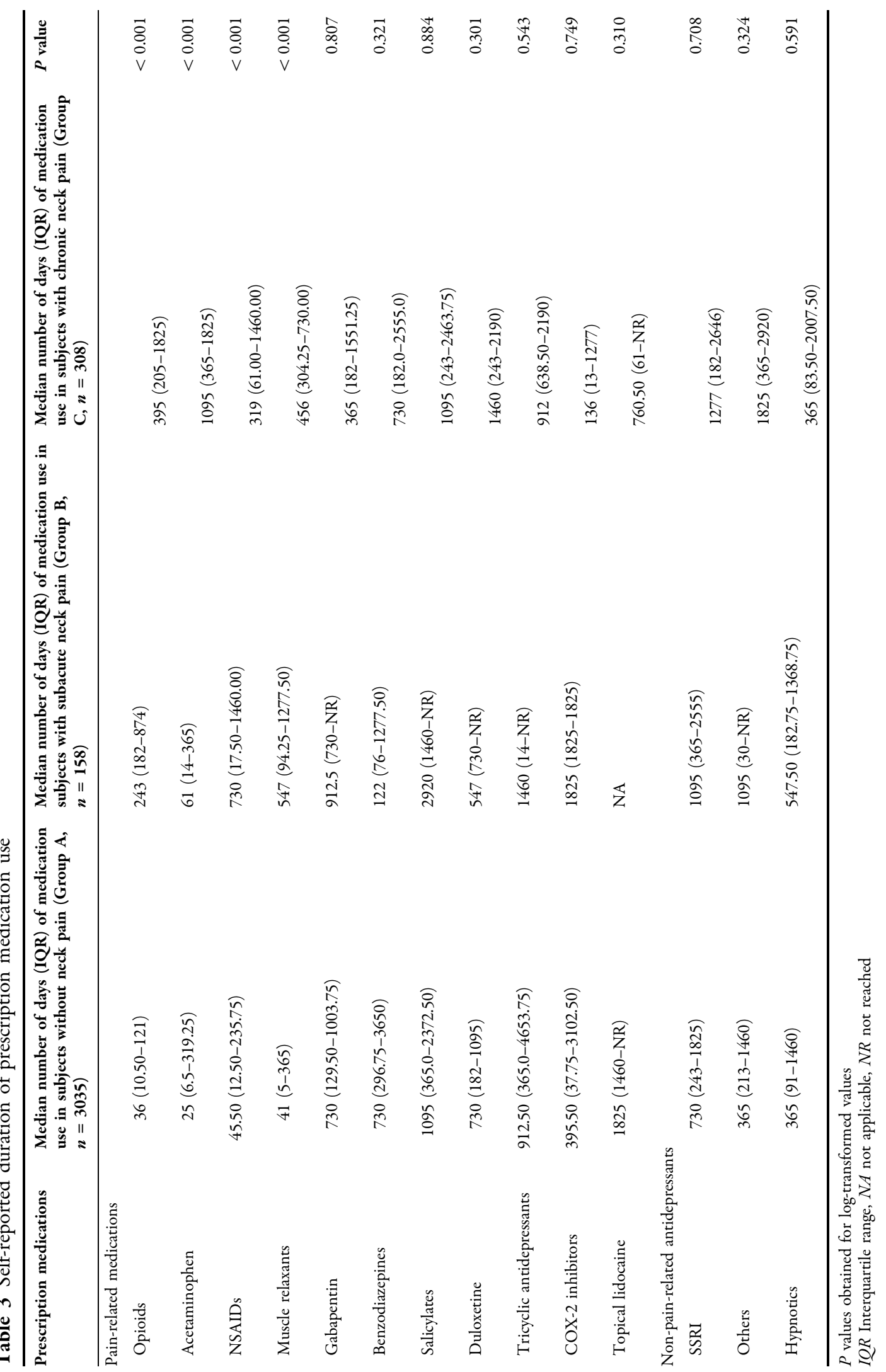


The efficacy of analgesics (Table 5) was also assessed. According to the self-report of the subjects, there was no significant difference between opioids and other commonly used analgesics $(P>0.05)$. In terms of life quality improvement, there was also no significant difference between opioids and other commonly used analgesics in terms of pain reduction, with the result being insomnia $(P>0.05)$. However, the results did reveal that NSAIDS had were more efficacious than acetaminophen for pain relief.

\section{DISCUSSION}

The aim of our study was to analyze the use of different prescription analgesics by U.S. adults with neck pain using real-world data. We found that opioids were the most common analgesics used for pain management by patients with neck pain and that they were used for a relatively longer time compared to other common analgesics. Previous studies have shown that during recent decades excessive use of opioid analgesics has been and still is a common and serious problem in the USA [19-21]. Although many professional medical societies have made appeals to reduce the use of opioids, the level of opioid use in the USA remains fourfold higher than the current prescription rate in Europe and threefold higher than it was 1999 [19, 22, 23]. Studies have demonstrated that the effect of oral opioids is not superior to that of NSAIDs in terms of reducing non-cancer pain in the short term $[24,25]$. Meredith et al. pointed out that there was no evidence of any long-term benefits of opioids in terms of reducing chronic noncancer pain [26]. In addition, opioids can lead to many adverse events, such as fractures, myocardial infarction, abuse, and opioid-induced hyperalgesia and tolerance $[27,28]$. The conclusion to be drawn from these studies is that opioids do not have the desired effect in reducing pain, but they do increase the risk of adverse events.

Earlier studies showed that there was a significant decrease in opioid use by patients with low back, neck, knee, and shoulder pain between 2008 and 2014 in the USA [29].
However, the extent of this decrease was not significant among patients with neck pain [29]. Machado et al. pointed out that there have been very few trials aimed at showing the effectiveness of NSAIDs on neck pain [30]. In one study, Peloso et al. showed that there was limited and unclear evidence the NSAIDs were effective in reducing neck pain [31]. However, despite the high incidence of neck pain were, there is still insufficient evidence to support specific interventions for conservative treatments [32-34]. Therefore, one possible explanation of why the extent of the decrease in opioid use was not significant among neck pain populations may be that there is a lack (or limited number) of high-quality trials demonstrating the effectiveness of non-opioid therapies [35]. Lin et al. noted that recent clinical guidelines universally recommend psychosocial assessment for musculoskeletal pain, with the exception of neck pain [36]. Psychological states have been shown to be significantly associated with the extent of opioid abuse [37, 38]. However, recommendations based on psychological status assessment of neck pain treatment have been contradictory, showing that the effect of psychological status in neck pain patients is not well understood. It has been pointed out that psychotherapy could reduce the risk of opioid misuse among chronic pain patients [39]. Based on all of these studies, it is possible that an underestimation of psychological factors may be another reason why patients with neck pain show an extended use of opioids. Consistent with the results reported by Friedman et al. [42], we found that in the USA low-income patients were more likely to use opioids [40]. Gangavalli et al. pointed out that low-income patients believe that they are not prescribed enough pain medications, including opioids [41]. Other factors also contribute to this result, including (1) unmeasured patient-level characteristics; (2) doctors' prescribing practices in low-income neighborhoods; (3) low-income patients not questioning the appropriateness of prolonged opioid treatment [42].

Opioid use and the use of other analgesics in combination with opioids increase with pain impact levels $[9,43,44]$. One study showed that early physical therapy for neck pain may 


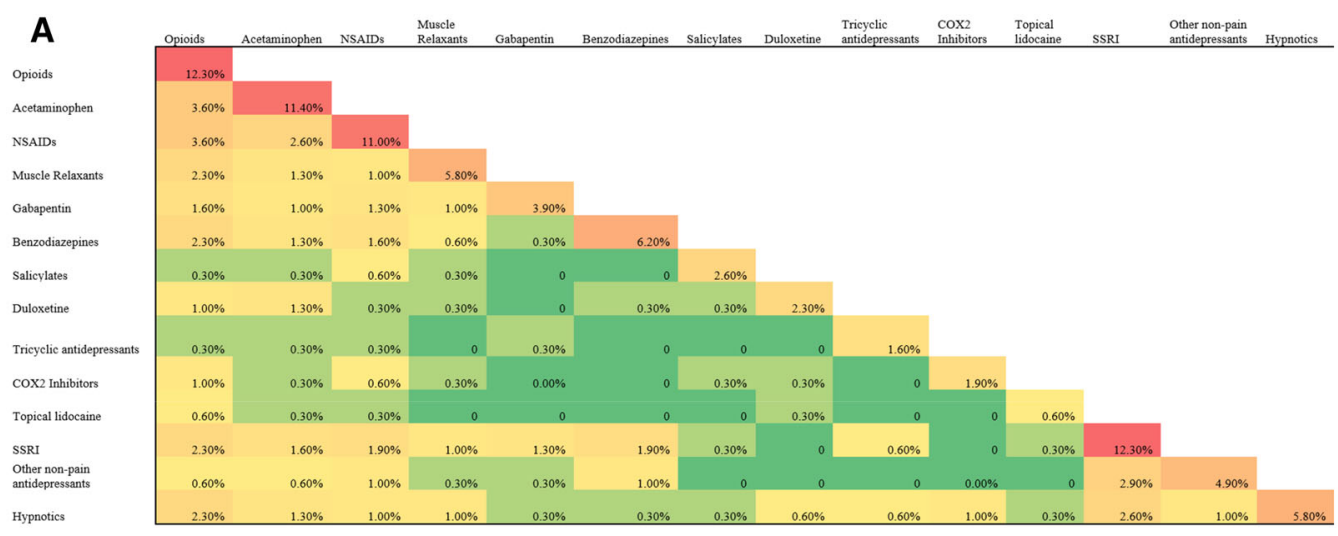

B

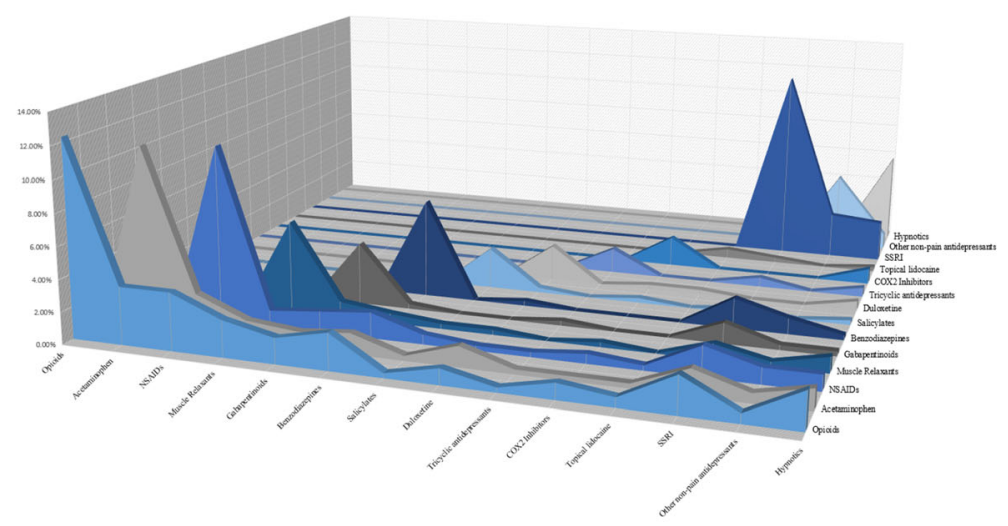

Fig. 1 Combinations of different medications used by U.S. adults with chronic neck pain. a Heat map, $\mathbf{b}$ area graph. a The most frequently co-administered medications are given in red and the least frequently co-administered medications are given in green. Note that some subjects

decrease total treatment costs and the use of prescription medicines, including opioids [45]. The authors of another study reported that early physical therapy may reduce both the frequency and level of opioid use for all of the musculoskeletal pain regions [46]. The conclusion to be drawn here is that early physical therapy or exercise therapy may be a good option to reduce the use of opioids and/or other analgesics when the pain level remains low.

Weeks et al. pointed out that patients with neck pain who use opioids are more likely to use pain medications and benzodiazepines [12]. This is similar to our results, which show that opioids are the most common analgesics that are used in combination with other analgesics. used more than two classes of medications at the same time. COX2 Cyclooxygenase 2, NSAIDs nonsteroidal antiinflammatory drugs, SSRI selective serotonin reuptake inhibitor

Some combinations of medications may may prolong the treatment effect and reduce opioid requirements [47]. However, the combination may also contribute to drug overdose when other analgesics are combined with opioids, thus increasing the risk of visits to the emergency department [48]. Therefore, it may be worth changing treatment preferences to reduce the initial use of opioids.

Our analysis also revealed that patients with lower education levels and from low-income families were more likely to use opioids for managing their neck pain. One possible explanation is that these populations are overly dependent on medications and that they lack an understanding of the exact effect of opioids 

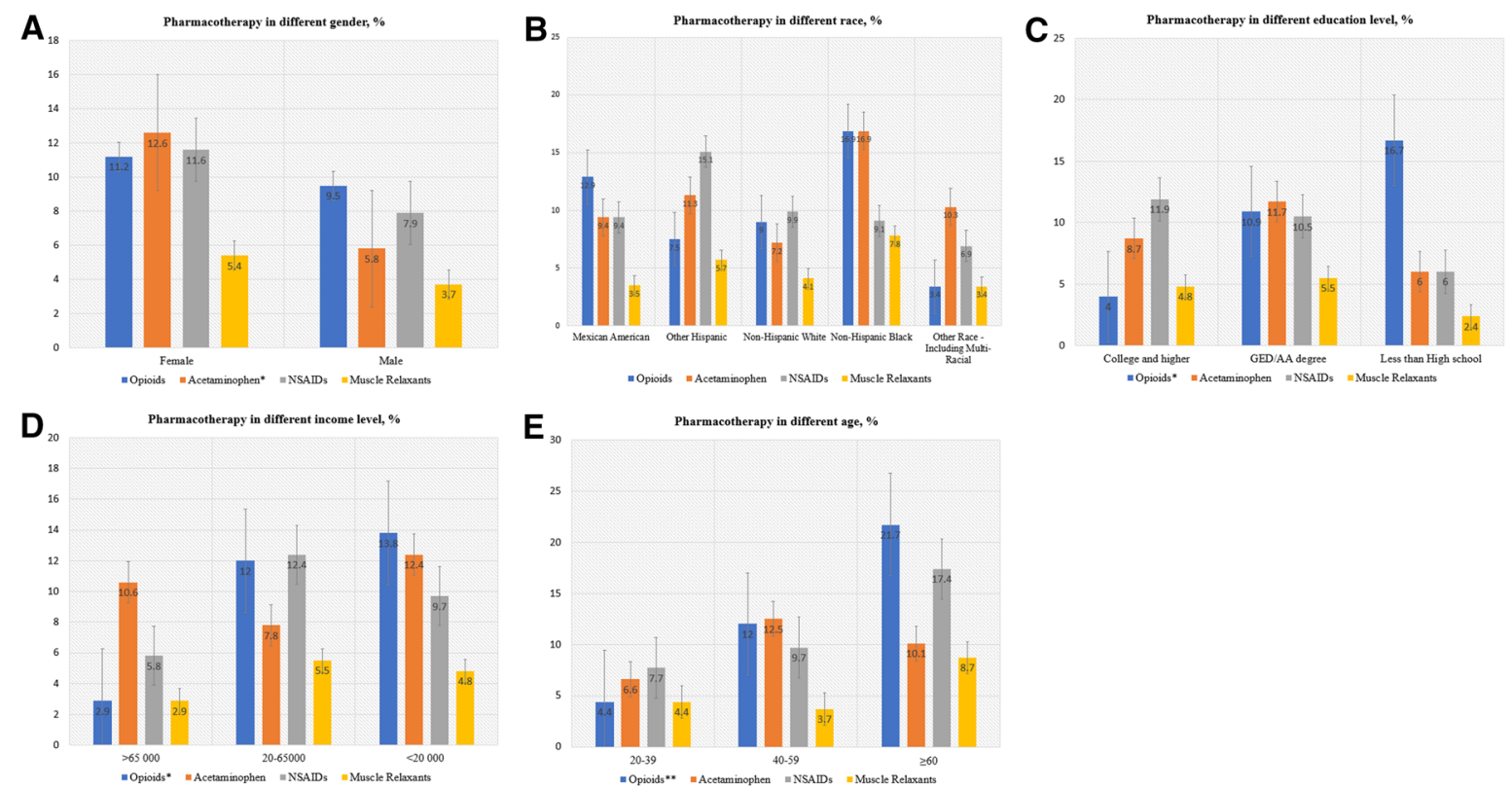

Fig. 2 Demographic distribution of pain medication use in U.S. adults with chronic neck pain. The bar charts illustrate the distribution of pain medication use in the chronic neck pain population by age (a), gender (b), race (c), family income (d), and education level (e). GED/AA

as well as their serious side effects. All recent guidelines for neck pain treatment recommend patient education programs, such as encouraging patients to return to normal activities as soon as possible, minimizing use of a cervical collar, and performing postural and mobility exercises, and non-pharmaceutical therapy before initiating a patient on pharmacotherapy [49-51]. Thus, healthcare professionals should encourage health education, especially for the patient populations mentioned above, and recommend non-pharmaceutical therapy, including exercise, manual therapy, and psychological therapy, as the first-line treatment. Takaki et al. reported that tobacco users were more likely than non-users to use opioid analgesics in combination with/without muscle relaxants and/or benzodiazepines for non-cancer pain [52]. Thus, healthcare professionals also should consider limiting opioid use by tobacco users.

Our results suggest that healthcare professionals should pay more attention to reducing opioid use in the neck pain population in
General educational development and Associate's degree (equivalent to high school diploma). Chi-square ${ }^{*} p<0.05$; ${ }^{* *} p<0.01$

general. However, there are issues to be addressed. First, in terms of the whole country, especially in low-income neighborhoods, doctors should unify and standardize treatment strategies. Second, a patient's socioeconomic background, such as education level and income, are crucial factors to be taken into consideration when choosing pharmacotherapy, and as such should be considered in the development of the clinical guideline. Third, doctors should make an extra effort to educate patients on the appropriate pain management strategies.

Regarding analgesic efficacy, we found that opioids were not more effective than acetaminophen or NSAIDs in terms of pain relief. This result is consistent with those of previous studies [53-55]. Drug overdose has been estimated to have caused 10,000-20,000 deaths in the USA; as well, the many other adverse effects of opioidso need to be considered [56, 57]. Although acetaminophen and NSAIDs also have some limitations, such as cardiovascular and 
Table 4 Adjusted odds ratio of demographic factors associated with pain medication use in U.S. adults with neck pain

\begin{tabular}{|c|c|c|c|c|}
\hline \multirow[t]{2}{*}{ Demographic factors } & \multicolumn{4}{|c|}{ Adjusted odds ratio (95\% CI) } \\
\hline & Opioids & Acetaminophen & NSAIDs & Muscle relaxants \\
\hline Age & $1.05(1.02-1.08)^{* *}$ & $1.01(0.98-1.04)$ & $1.02(0.99-1.04)$ & $1.02(0.99-1.06)$ \\
\hline \multicolumn{5}{|l|}{ Gender } \\
\hline Female & REF & REF & REF & REF \\
\hline Male & $0.87(0.44-1.71)$ & $0.45(0.22-0.91)^{*}$ & $0.77(0.39-1.51)$ & $0.72(0.28-1.84)$ \\
\hline \multicolumn{5}{|l|}{ Race } \\
\hline Mexican American & REF & REF & REF & REF \\
\hline Other Hispanic & $0.36(0.10-1.35)$ & $1.17(0.37-3.73)$ & $1.40(0.47-4.17)$ & $1.50(0.28-7.96)$ \\
\hline Non-Hispanic white & $0.66(0.28-1.57)$ & $0.79(0.32-1.96)$ & $1.00(0.42-2.41)$ & $1.13(0.30-4.34)$ \\
\hline Non-Hispanic black & $1.31(0.49-3.50)$ & $2.01(0.75-5.35)$ & $0.87(0.29-2.62)$ & $2.02(0.48-8.63)$ \\
\hline Other race-including multi-racial & $0.33(0.04-2.88)$ & $1.25(0.30-5.24)$ & $0.67(0.13-3.57)$ & $1.02(0.10-10.54)$ \\
\hline \multicolumn{5}{|l|}{ Education } \\
\hline College and higher & REF & REF & REF & REF \\
\hline GED/AA degree & $2.27(1.02-5.19)^{*}$ & $1.51(0.70-3.26)$ & $0.96(0.47-1.95)$ & $1.26(0.45-3.51)$ \\
\hline Less than high school & $4.12(1.40-12.1)^{*}$ & $0.75(0.24-2.41)$ & $0.59(0.19-1.77)$ & $0.60(0.11-3.27)$ \\
\hline \multicolumn{5}{|l|}{ Annual family income (US\$) } \\
\hline$>65,000$ & REF & REF & REF & REF \\
\hline $20-65,000$ & $5.40(1.52-19.22)^{* *}$ & $0.60(0.26-1.39)$ & $1.86(0.72-4.79)$ & $1.71(0.46-6.43)$ \\
\hline$<20,000$ & $5.88(1.55-22.25)^{*}$ & $0.98(0.41-2.37)$ & $1.12(0.39-3.25)$ & $1.42(0.33-6.16)$ \\
\hline \multicolumn{5}{|l|}{ Medical comorbidities } \\
\hline $0-1$ & REF & REF & REF & REF \\
\hline $2-3$ & $0.86(0.41-1.82)$ & $1.46(0.74-2.90)$ & $1.78(0.91-3.46)$ & $1.64(0.65-4.14)$ \\
\hline$>3$ & $3.58(1.30-9.89)^{*}$ & $2.28(0.72-7.24)^{*}$ & $1.18(0.35-4.06)$ & $0.73(0.08-6.43)$ \\
\hline PHQ9 score (depression) & $1.04(0.99-1.08)$ & $0.99(0.95-1.04)$ & $1.05(1.01-1.09)^{*}$ & $0.99(0.92-1.06)$ \\
\hline
\end{tabular}

$G E D / A A$ General educational development and Associate's degree (equivalent to high school diploma), $R E F$ reference ${ }^{*} P<0.05 ;{ }^{* *} P<0.01$

renal toxicity, hypertension, and gastrointestinal damage, restrictions to the use of step 3 analgesics (i.e. strong-acting opoids) in patients with non-cancer pain is urgent [58]. However, if other analgesics are truly ineffective, it remains legitimate and even advisable to use opioids for short periods ( $<3$ months) [59]. We also found that the NSAIDS were more efficacious that acetaminophen in terms of neck pain relief. Previous studies also pointed out that acetaminophen has a very small analgesic effect when compared with NSAIDs in musculoskeletal diseases, while acetaminophen has similar side effects with NSAIDs [60, 61]. In our study, we found the usage of COX-2 inhibitors remains low among patients with neck pain 


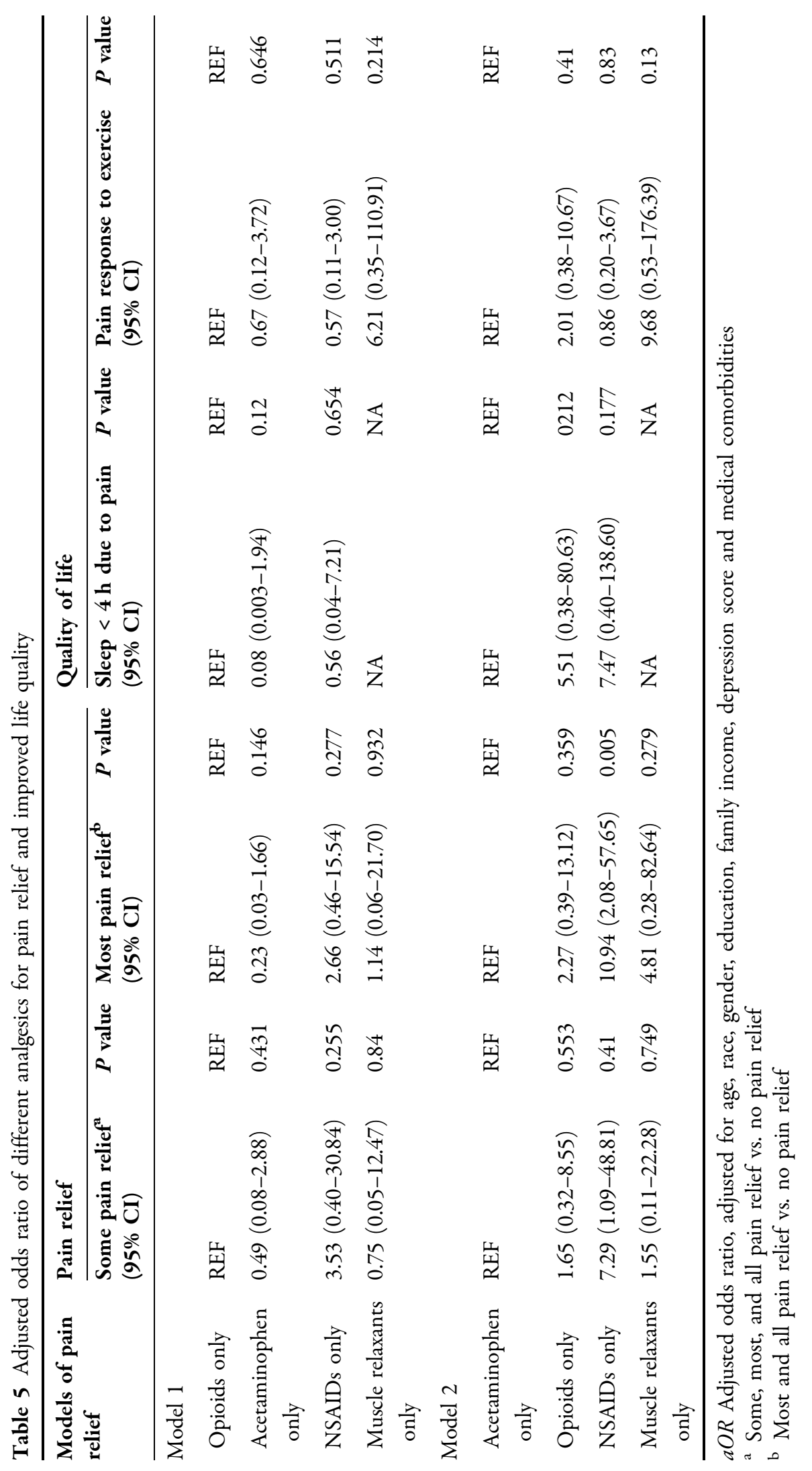


patients. However, COX-2 inhibitors have similar analgesic effects as traditional NSAIDs but with lower gastrointestinal and cardiovascular toxicity $[61,62]$. Therefore, COX-2 inhibitors may be a promising pharmacotherapy for the management of musculoskeletal pain. However, more clinical trials in this area and relative clinical guidelines are needed.

Our study is based on real-world data and shows the specific prescription medication use pattern among U.S. adults with neck pain. Our results reveal the potential problem in pharmacotherapy choices for neck pain treatment and may help improve the current clinical practice in the USA and other countries.

\section{Limitations}

There are a number of limitations to this study. First, our data included some self-reported variables which may lead to measurement error and recall bias. Second, the specific dosage and frequency of each prescription medication could not be evaluated, which impedes further study of the rate of drug abuse because the database does not provide these data. Third, some of the participants may have concealed their medication history, and thus the use of some of the medications may be underestimated. Lastly, it is not clear if the analgesics were used only for neck pain, which may lead to an overestimation of the usage rate of prescription medications.

\section{CONCLUSION}

Previous studies have shown that excessive long-term use of opioids and underutilization of other analgesics are two major issues in the treatment of neck pain in the USA. In our study, patients with a lower education level and low family income were more likely to use opioids to reduce neck pain. Possible improvements could be better patient education by healthcare professionals on the use of opoiods and more consideration given to non-pharmacotherapy options to reduce opioid dependence and the related side effects of opioids as recommended by recent guidelines. Our results reveal the potential problem in pharmacotherapy choices for neck pain treatment and may help improve the current clinical practice in America and other countries.

\section{ACKNOWLEDGEMENTS}

Funding. This work and the journal's Rapid Service Fee were funded by the National Natural Science Foundation of China (31600769, 81501933), Wenzhou Municipal Science and Technology Bureau (Y20190018), Wenzhou leading talent innovative project (RX2016004), Zhejiang Provincial Medical Technology Foundation of China (2018KY129), Higher Education Teaching Reform Project of Wenzhou Medical University (YBJG201826), Zhejiang Provincial Traditional Chinese Medicine Science and Technology Program (2020ZB146). The funders had no role in the design, execution, and writing up of the study.

Authorship. All named authors meet the International Committee of Medical Journal Editors (ICMJE) criteria for authorship for this article, take responsibility for the integrity of the work as a whole, and have given their approval for this version to be published.

Authorship Contributions. Jin-Feng Huang, Yan Michael Li, and Ai-Min $\mathrm{Wu}$ designed the study. Jin-Feng Huang, Zhou Meng, Xuan-Qi Zheng, and Zongshi Qin developed and tested the data collection forms. Jin-Feng Huang, Zhou Meng, Xuan-Qi Zheng, Zongshi Qin, and AiMin $\mathrm{Wu}$ acquired the data. Jin-Feng Huang, Xuan-Qi Zheng, Zhou Meng, Zongshi Qin, Xiao-Lei Sun, Kai Zhang, Hai-Jun Tian, XiaoBing Wang, and Ze Gao conducted the analysis and interpreted the data. Jin-Feng Huang, Yan Michael Li, and Ai-Min Wu drafted the manuscript. All authors critically revised the manuscript.

Disclosures. Jin-Feng Huang, Zhou Meng, Xuan-Qi Zheng, Zongshi Qin, Xiao-Lei Sun, Kai Zhang, Hai-Jun Tian, Xiao-Bing Wang, Ze Gao, 
Yan Michael Li and Ai-Min Wu have nothing to disclose.

Compliance with Ethics Guidelines. All data were obtained from NHANES directly in deidentified form, and thus this study did not require additional Institutional Review Board approval.

Data Availability. The datasets generated during and analyzed during the current study are available in the National Health and Nutrition Examination Survey (NHANES), https:// www.cdc.gov/nchs/nhanes/index.htm.

Open Access. This article is licensed under a Creative Commons Attribution-NonCommercial 4.0 International License, which permits any non-commercial use, sharing, adaptation, distribution and reproduction in any medium or format, as long as you give appropriate credit to the original author(s) and the source, provide a link to the Creative Commons licence, and indicate if changes were made. The images or other third party material in this article are included in the article's Creative Commons licence, unless indicated otherwise in a credit line to the material. If material is not included in the article's Creative Commons licence and your intended use is not permitted by statutory regulation or exceeds the permitted use, you will need to obtain permission directly from the copyright holder. To view a copy of this licence, visit http://creativecommons.org/licenses/bync/4.0/.

\section{REFERENCES}

1. Safiri S, Kolahi A-A, Hoy D, et al. Global, regional, and national burden of neck pain in the general population, 1990-2017: systematic analysis of the Global Burden of Disease Study 2017. BMJ. 2020;368:m791. https://doi.org/10.1136/bmj.m791.

2. Murray CJ, Atkinson C, Bhalla K, et al. The state of US health, 1990-2010: burden of diseases, injuries, and risk factors. JAMA. 2013;310(6):591-608. https://doi.org/10.1001/jama.2013.13805.
3. Fejer R, Kyvik KO, Hartvigsen J. The prevalence of neck pain in the world population: a systematic critical review of the literature. Eur Spine J. 2006;15(6):834-48. https://doi.org/10.1007/s0058 6-004-0864-4.

4. Cohen SP. Epidemiology, diagnosis, and treatment of neck pain. Mayo Clin Proc. 2015;90(2):284-99. https://doi.org/10.1016/j.mayocp.2014.09.008.

5. Parikh P, Santaguida P, Macdermid J, Gross A, Eshtiaghi A. Comparison of CPG's for the diagnosis, prognosis and management of non-specific neck pain: a systematic review. BMC Musculoskelet Disord. 2019;20(1):81. https://doi.org/10.1186/s12891019-2441-3.

6. Machado GC, Maher CG, Ferreira PH, et al. Efficacy and safety of paracetamol for spinal pain and osteoarthritis: systematic review and meta-analysis of randomised placebo controlled trials. BMJ. 2015;350:h1225. https://doi.org/10.1136/bmj. h1225.

7. Dowell D, Haegerich TM, Chou R. CDC guideline for prescribing opioids for chronic pain-United States, 2016. JAMA. 2016;315(15):1624-45.

8. Setchell J, Costa N, Ferreira M, Makovey J, Nielsen M, Hodges PW. Individuals' explanations for their persistent or recurrent low back pain: a cross-sectional survey. BMC Musculoskelet Disord. 2017;18(1):466-466.

9. Herman PM, Broten N, Lavelle TA, Sorbero ME, Coulter ID. Health care costs and opioid use associated with high-impact chronic spinal pain in the United States. Spine (Phila Pa 1976). 2019;44(16): 1154-61. https://doi.org/10.1097/BRS.0000000000 003033.

10. Kim HS, Kaplan SH, McCarthy DM, et al. A comparison of analgesic prescribing among ED back and neck pain visits receiving physical therapy versus usual care. Am J Emerg Med. 2019;37(7):1322-6. https://doi.org/10.1016/j.ajem.2018.10.009.

11. Fischbein R, McCormick K, Selius BA, et al. The assessment and treatment of back and neck pain: an initial investigation in a primary care practice-based research network. Prim Health Care Res Dev. 2015;16(5):461-9. https://doi.org/10.1017/ S1463423614000504.

12. Weeks WB, Goertz CM, Long CR, Meeker WC, Marchiori DM. Association among opioid use, treatment preferences, and perceptions of physician treatment recommendations in patients with neck and back pain. J Manipulative Physiol Ther. 2018;41(3):175-80. https://doi.org/10.1016/j.jmpt. 2017.12.003. 
13. Nielsen S, Roxburgh A, Bruno R, Lintzeris N, Jefferson A, Degenhardt L. Changes in non-opioid substitution treatment episodes for pharmaceutical opioids and heroin from 2002 to 2011. Drug Alcohol Depend. 2015;149:212-9.

14. Kotecha MK, Sites BD. Pain policy and abuse of prescription opioids in the USA: a cautionary tale for Europe. Anaesthesia. 2013;68(12):1210-5.

15. Sherman RE, Anderson SA, Dal Pan GJ, et al. Realworld evidence-what is it and what can it tell us? N Engl J Med. 2016;375(23):2293-7. https://doi. org/10.1056/NEJMsb1609216.

16. Boyle M, Buckley JP, Quirós-Alcalá L. Associations between urinary organophosphate ester metabolites and measures of adiposity among U.S. children and adults: NHANES 2013-2014. Environ Int. 2019;127:754-63. https://doi.org/10.1016/j.envint. 2019.03.055.

17. Borrud L, Chiappa MM, Burt VL, et al. National Health and Nutrition Examination Survey: national youth fitness survey plan, operations, and analysis, 2012. Vital Health Stat 2. 2014;(163):1-24.

18. Bart G. Maintenance medication for opiate addiction: the foundation of recovery. J Addict Dis. 2012;31(3):207-25.

19. Guy GP Jr, Zhang K, Bohm MK, et al. Vital signs: changes in opioid prescribing in the United States, 2006-2015. MMWR Morb Mortal Wkly Rep. 2017;66(26):697-704. https://doi.org/10.15585/ mmwr.mm6626a4.

20. Stokes A, Berry KM, Hempstead K, Lundberg DJ, Neogi T. Trends in prescription analgesic use among adults with musculoskeletal conditions in the United States, 1999-2016. JAMA Netw Open. 2019;2(12):e1917228. https://doi.org/10.1001/ jamanetworkopen.2019.17228.

21. Tomaszewski DM, Arbuckle C, Yang S, Linstead E. Trends in opioid use in pediatric patients in US emergency departments from 2006 to 2015. JAMA Netw Open. 2018;1(8):e186161. https://doi.org/10. 1001/jamanetworkopen.2018.6161.

22. Rao S, Rao S, Harvey HB, Avery L, Saini S, Prabhakar AM. Low back pain in the emergency departmentare the ACR appropriateness criteria being followed? J Am Coll Radiol. 2015;12(4):364-9.

23. Centers for Disease Control and Prevention (CDC). Vital signs: overdoses of prescription opioid pain relievers-United States, 1999-2008. MMWR Morb Mortal Wkly Rep. 2011;60(43):1487-92.

24. Berthelot JM, Darrieutort-Lafitte C, Le Goff B, Maugars Y. Strong opioids for noncancer pain due to musculoskeletal diseases: not more effective than acetaminophen or NSAIDs. Joint Bone Spine. 2015;82(6):397-401. https://doi.org/10.1016/j. jbspin.2015.08.003.

25. Furlan AD, Sandoval JA, Mailis-Gagnon A, Tunks E. Opioids for chronic noncancer pain: a meta-analysis of effectiveness and side effects. CMAJ. 2006;174(11):1589-94. https://doi.org/10.1503/ cmaj.051528.

26. Noble M, Treadwell JR, Tregear SJ, et al. Long-term opioid management for chronic noncancer pain. Cochrane Database Syst Rev. 2010;2010(1): CD006605. https://doi.org/10.1002/14651858. CD006605.pub2.

27. Chou R, Qaseem A, Snow V, et al. Diagnosis and treatment of low back pain: a joint clinical practice guideline from the American College of Physicians and the American Pain Society [published correction appears in Ann Intern Med. 2008 Feb 5;148(3): 247-8]. Ann Intern Med. 2007;147(7):478-91. https://doi.org/10.7326/0003-4819-147-7-2007100 20-00006.

28. Hooten WM, Lamer TJ, Twyner C. Opioid-induced hyperalgesia in community-dwelling adults with chronic pain. Pain. 2015;156(6):1145-52. https:// doi.org/10.1097/j.pain.0000000000000170.

29. Moshfegh J, George SZ, Sun E. Risk and risk factors for chronic opioid use among opioid-naive patients with newly diagnosed musculoskeletal pain in the neck, shoulder, knee, or low back. Ann Intern Med. 2019;170(7):504-5. https://doi.org/10.7326/M182261.

30. Machado GC, Maher CG, Ferreira PH, Day RO, Pinheiro MB, Ferreira ML. Non-steroidal anti-inflammatory drugs for spinal pain: a systematic review and meta-analysis. Ann Rheum Dis. 2017;76(7):1269-78.

31. Peloso P, Gross A, Haines T, Trinh K, Goldsmith $\mathrm{CH}$, Burnie $\mathrm{S}$. Medicinal and injection therapies for mechanical neck disorders. Cochrane Database Syst Rev. 2007;3:Cd000319.

32. Heintz MM, Hegedus EJ. Multimodal management of mechanical neck pain using a treatment based classification system. J Man Manip Ther. 2008;16(4):217-24.

33. Chiu TT, Lam TH, Hedley AJ. A randomized controlled trial on the efficacy of exercise for patients with chronic neck pain. Spine. 2005;30(1):E1-7.

34. de Araujo CL, Jones A, Roger-Silva D, Ribeiro LHC, Natour J. Effectiveness of the pilates method in the treatment of chronic mechanical neck pain: a 
randomized controlled trial. Arch Phys Med Rehabil. 2018;99(9):1740-6.

35. Wong JJ, Côté P, Ameis A, et al. Are non-steroidal anti-inflammatory drugs effective for the management of neck pain and associated disorders, whiplash-associated disorders, or non-specific low back pain? A systematic review of systematic reviews by the Ontario Protocol for Traffic Injury Management (OPTIMa) Collaboration. Eur Spine J. 2016;25(1): 34-61.

36. Lin I, Wiles L, Waller R, et al. What does best practice care for musculoskeletal pain look like? Eleven consistent recommendations from highquality clinical practice guidelines: systematic review. Br J Sports Med. 2020;54(2):79-86.

37. Boyd CJ, Young A, McCabe SE. Psychological and drug abuse symptoms associated with nonmedical use of opioid analgesics among adolescents. Subst Abus. 2014;35(3):284-9.

38. Ris I, Barbero M, Falla D, et al. Pain extent is more strongly associated with disability, psychological factors, and neck muscle function in people with non-traumatic versus traumatic chronic neck pain: a cross sectional study. Eur J Phys Rehabil Med. 2019;55(1):71-8.

39. Garland EL, Hanley AW, Riquino MR, et al. Mindfulness-oriented recovery enhancement reduces opioid misuse risk via analgesic and positive psychological mechanisms: a randomized controlled trial. J Consult Clin Psychol. 2019;87(10):927-40.

40. Friedman J, Kim D, Schneberk T, et al. Assessment of racial/ethnic and income disparities in the prescription of opioids and other controlled medications in California. JAMA Intern Med. 2019;179(4): 469-76.

41. Gangavalli A, Malige A, Terres G, Rehman S, Nwachuku C. Misuse of opioids in orthopaedic postoperative patients. J Orthop Trauma. 2017;31(4): e103-e109109.

42. Clarke H, Soneji N, Ko DT, Yun L, Wijeysundera DN. Rates and risk factors for prolonged opioid use after major surgery: population based cohort study. BMJ. 2014;348:g1251.

43. Taylor-Stokes G, Lobosco S, Pike J, Sadosky AB, Ross E. Relationship between patient-reported chronic low back pain severity and medication resources. Clin Ther. 2011;33(11):1739-48. https://doi.org/10. 1016/j.clinthera.2011.09.026.

44. Von Korff M, Ormel J, Keefe FJ, Dworkin SF. Grading the severity of chronic pain. Pain. 1992;50(2): 133-49. https://doi.org/10.1016/0304-3959(92)901 54-4.
45. Horn ME, Fritz JM. Timing of physical therapy consultation on 1-year healthcare utilization and costs in patients seeking care for neck pain: a retrospective cohort. BMC Health Serv Res. 2018;18(1):887. https://doi.org/10.1186/s12913018-3699-0.

46. Sun E, Moshfegh J, Rishel CA, Cook CE, Goode AP, George SZ. Association of early physical therapy with long-term opioid use among opioid-naive patients with musculoskeletal pain. JAMA Netw Open. 2018;1(8):e185909. https://doi.org/10.1001/ jamanetworkopen.2018.5909.

47. Raffa RB. Pharmacology of oral combination analgesics: rational therapy for pain. J Clin Pharm Ther. 2001;26(4):257-64. https://doi.org/10.1046/j.13652710.2001.00355.x.

48. Willy M, Kelly JP, Nourjah P, Kaufman DW, Budnitz DS, Staffa J. Emergency department visits attributed to selected analgesics, United States, 2004-2005. Pharmacoepidemiol Drug Saf. 2009;18(3):188-95. https://doi.org/10.1002/pds.1691.

49. Bier JD, Scholten-Peeters WGM, Staal JB, et al. Clinical practice guideline for physical therapy assessment and treatment in patients with nonspecific neck pain. Phys Ther. 2018;98(3):162-71. https://doi.org/10.1093/ptj/pzx118.

50. Blanpied PR, Gross AR, Elliott JM, et al. Neck pain: revision 2017. J Orthop Sports Phys Ther. 2017;47(7):A1-83. https://doi.org/10.2519/jospt. 2017.0302 .

51. Monticone M, Iovine R, de Sena G, et al. The Italian Society of Physical and Rehabilitation Medicine (SIMFER) recommendations for neck pain. G Ital Med Lav Ergon. 2013;35(1):36-50.

52. Takaki H, Ieiri I, Shibuta H, Onozuka D, Hagihara A. The association of tobacco use with prescription of muscle relaxants, benzodiazepines, and opioid analgesics for non-cancer pain. Am J Addict. 2019;28(2):63-70. https://doi.org/10.1111/ajad. 12830 .

53. Khoromi S, Cui L, Nackers L, Max MB. Morphine, nortriptyline and their combination vs. placebo in patients with chronic lumbar root pain. Pain. 2007;130(1):66-75.

54. Chung JW, Zeng Y, Wong TK. Drug therapy for the treatment of chronic nonspecific low back pain: systematic review and meta-analysis. Pain Phys. 2013;16(6):E685-704.

55. Myers J, Wielage RC, Han B, et al. The efficacy of duloxetine, non-steroidal anti-inflammatory drugs, and opioids in osteoarthritis: a systematic literature 
review and meta-analysis. BMC Musculoskelet Disord. 2014;15:76.

56. Alexander GC, Kruszewski SP, Webster DW. Rethinking opioid prescribing to protect patient safety and public health. JAMA. 2012;308(18): 1865-6.

57. Schiltenwolf M, Akbar M, Hug A, et al. Evidence of specific cognitive deficits in patients with chronic low back pain under long-term substitution treatment of opioids. Pain Phys. 2014;17(1):9-20.

58. Kuehn BM. Petition targets painkiller marketing in effort to curb overdose deaths. JAMA. 2012;308(12): 1194-6.

59. Berthelot JM, Darrieutort-Lafitte C, Le Goff B, Maugars Y. Strong opioids for noncancer pain due to musculoskeletal diseases: not more effective than acetaminophen or NSAIDs. Jt Bone Spine. 2015;82(6):397-401.

60. Bannuru RR, Schmid CH, Kent DM, Vaysbrot EE, Wong JB, McAlindon TE. Comparative effectiveness of pharmacologic interventions for knee osteoarthritis: a systematic review and network meta-analysis. Ann Intern Med. 2015;162(1):46-544.

61. Richette P, Latourte A, Frazier A. Safety and efficacy of paracetamol and NSAIDs in osteoarthritis: which drug to recommend? Expert Opin Drug Saf. 2015;14(8):1259-68.

62. Bakhriansyah M, Souverein PC, de Boer A, Klungel $\mathrm{OH}$. Gastrointestinal toxicity among patients taking selective COX-2 inhibitors or conventional NSAIDs, alone or combined with proton pump inhibitors: a case-control study. Pharmacoepidemiol Drug Saf. 2017;26(10):1141-8. 